\title{
GUIANA FRANCESA E MALVINAS: A PRESENÇA MILITAR DA FRANÇA E DO REINO UNIDO NO ATLÂNTICO SUL E NO CONTINENTE SUL-AMERICANO
}

Marcos Valle Machado da Silva'

\section{Introdução}

As dimensões continentais do território brasileiro, tendo fronteiras com io países, bem como os 3,5 milhões de $\mathrm{km}^{2}$ das Águas Jurisdicionais Brasileiras (AJB) ${ }^{2}$ são fatores que configuram a América do Sul e o Atlântico Sul como a área de interesse prioritário do Estado brasileiro, nas questões afetas à defesa nacional.

O Atlântico Sul permite o acesso às principais portas de entrada e saída do comércio exterior brasileiro e está cada vez mais ligado ao desenvolvimento econômico nacional, seja por meio da exploração de petróleo, gás e pesca, ou como via de comércio nacional e internacional. As águas do Atlântico Sul têm a singular característica de que, exceto pela questão das Malvinas, são

I Professor da Escola de Guerra Naval (EGN). Doutor em Ciência Política pela Universidade Federal Fluminense (UFF). Mestre em Relações Internacionais pela Universidade do Estado do Rio de Janeiro (UERJ). Email: mbvalle2002@yahoo.com.br

2 O termo “Águas Jurisdicionais Brasileiras (AJB)” é utilizado neste artigo em consonância com conceito apresentado no Livro Branco de Defesa Nacional (LBDN), a seguir transcrito: "Compreende as águas interiores e os espaços marítimos, nos quais o Brasil exerce jurisdição, em algum grau, sobre atividades, pessoas, instalações, embarcações e recursos naturais vivos e não vivos, encontrados na massa líquida, no leito ou no subsolo marinho, para os fins de controle e fiscalização, dentro dos limites da legislação internacional e nacional. Esses espaços marítimos compreendem a faixa de 200 milhas marítimas contadas a partir das linhas bases, acrescidas das águas sobrejacentes à extensão da Plataforma Continental além das 200 milhas marítimas, onde ela ocorrer" (Brasil 20I6b, I5). 
usualmente percebidas como livres das tradicionais ameaças decorrentes de conflitos militares de caráter interestatal ${ }^{3}$. Entre os Estados sul-americanos, não existem disputas por soberania ou jurisdição em relação ao Atlântico Sul. No entanto, dois estados exógenos a região estão presentes, tanto no continente sul-americano, quanto em ilhas no Atlântico Sul. São eles: a França e o Reino Unido.

A França mantém uma colônia no continente sul-americano, com o status de Departamento Ultramarino, com contingente e instalações militares, usualmente ignorados nas análises afetas à presença militar de atores extrarregionais na América do Sul. Já o Reino Unido com suas possessões insulares no eixo norte-sul do Atlântico do Sul, englobando as ilhas de Ascensão, Santa Helena, Tristão da Cunha, Malvinas, Geórgia do Sul e Sandwich do Sul, desponta como Estado causador do principal foco de tensão no Atlântico Sul em função, principalmente, da questão da soberania sobre as Malvinas com a Argentina.

Neste contexto, cabe questionar: a presença militar desses atores extrarregionais gera tensões atuais e potenciais em relação à visão brasileira de defesa regional?

Buscando responder à questão proposta, este artigo tem como objetivo evidenciar a presença militar da França e do Reino Unido na América e Atlântico Sul e analisar as tensões decorrentes dessa presença, em relação à visão brasileira de defesa para a região.

O argumento central desenvolvido e defendido é o de que a presença militar da França na Guiana Francesa e do Reino Unido nas Malvinas têm o potencial para gerar tensões e crises, contrárias à visão de defesa brasileira para a América do Sul e Atlântico Sul.

Para responder à questão formulada e sustentar o argumento enunciado, bem como para a consecução do objetivo proposto, o texto está dividido em três seções. Na primeira, é identificada qual é a visão de defesa brasileira para a América do Sul e para o Atlântico Sul. Para tanto, foram analisados os documentos de defesa de mais alto nível do Estado brasileiro, em suas diversas atualizações, isto é, a Política Nacional de Defesa (PND) e a Estratégia Nacional de Defesa (END).

3 O termo conflito interestatal é aqui utilizado em seu sentido amplo, tal como apresentado no Glossary of Terms and Concepts in Peace and Conflict Studies (Miller 2005, 22), publicado pela University of Peace: "Os conflitos interestatais são disputas entre Estados ou violações do sistema de alianças feitas entre Estados" (Tradução nossa). No original: "Interstate conflicts are disputes between nation-states or violations of the state system of alliances."

O termo conflito militar interestatal é usado aqui para significar esse tipo de conflito em que a força militar é usada ou existe a ameaça de usá-la por um dos estados envolvidos no conflito. 
As duas seções seguintes têm como foco a análise dos meios, efetivos e as principais instalações militares do Reino Unido e da França, em suas possessões na América do Sul e no Atlântico Sul, bem como os propósitos declarados por estes Estados para justificar a sua presença na região. Nessas duas seções são também identificadas as tensões, existentes e potenciais, decorrentes da presença militar britânica e francesa no entorno estratégico brasileiro. Nas Considerações Finais é evidenciado como as tensões decorrentes da presença militar, dos dois atores extrarregionais analisados, interferem com a visão de defesa brasileira para a região.

\section{A Visão de Defesa do Estado Brasileiro para a América do Sul e Atlântico Sul}

O Brasil possui um conjunto de documentos relativos à política e à estratégia de defesa, emanados do poder executivo, aprovados pelo legislativo e revisados periodicamente com participação de políticos, militares, acadêmicos, diplomatas e outros representantes da sociedade civil. Em ordem de precedência estes documentos são: a Política Nacional de Defesa (PND), a Estratégia de Nacional de Defesa (END) e o Livro Branco de Defesa Nacional (LBDN).

Tal como exposto na edição de 20I6, a "PND é o documento de mais alto nível do País em questões de Defesa, baseado nos princípios constitucionais e alinhado às aspirações e aos Objetivos Nacionais Fundamentais, que consolida os posicionamentos do Estado brasileiro e estabelece os objetivos mais elevados neste tema." (Brasil 20I6c).

O documento foi concebido originalmente em I996, com o nome de Política de Defesa Nacional (PDN), foi atualizado em 2005 e em 2012, ano em que teve seu título alterado para Política Nacional de Defesa (PND). Em 20I6, consonante com a legislação em vigor ${ }^{4}$, a PND passou por novo processo de atualização. Essa versão foi encaminhada para apreciação do Congresso Nacional, em novembro de 2016 e disponibilizada para consulta publica, pelo Ministério da Defesa. ${ }^{5}$

Já a Estratégia Nacional de Defesa orienta os segmentos do Estado

\footnotetext{
4 A Lei Complementar (LC) nffl 97/1999, alterada pela LC nffl i36/2010, no parágrafo terceiro do seu artigo nono, determina que o Poder Executivo encaminhe para a apreciação do Congresso Nacional, a cada quatro anos, a partir do ano de 20I2, as atualizações da PND, END e LBDN (Brasil 20I0).

5 Vide Brasil 20ı6c.
}

114 Austral: Revista Brasileira de Estratégia e Relações Internacionais v.7, n.14, Jul./Dez. 2018 
brasileiro quanto às ações que devem ser implementadas para que os Objetivos Nacionais de Defesa ${ }^{6}$ sejam alcançados. Sua primeira versão foi elaborada em 2008 , sendo atualizada em 2012 e em 2016.7

O Livro Branco de Defesa Nacional é o documento que contextualiza de forma ampla a Estratégia Nacional de Defesa, em perspectiva de médio e longo prazo, permitindo também o acompanhamento da evolução orçamentária e do planejamento plurianual dos principais projetos de defesa do Estado brasileiro (Brasil, 2010).

Feitas essas considerações iniciais sobre os principais documentos de domínio público, relativos à defesa nacional brasileira passaremos à análise das edições da PND e da END, buscando identificar qual é a visão de defesa brasileira para a América do Sul e para o Atlântico Sul. O eixo analítico central consistiu em identificar como a América do Sul e o Atlântico Sul são percebidos nesses documentos, quais são os Objetivos Nacionais de Defesa para essa região, bem como se existem Estratégias de Defesa para a sua consecução.

Analisando a Política Nacional de Defesa constata-se, em suas quatro edições (I996, 2005, 20I2 e 20I6), nos respectivos capítulos dedicados à análise do ambiente internacional e regional, que a América do Sul e o Atlântico Sul integram o chamado entorno estratégico brasileiro. ${ }^{8}$

A América do Sul é percebida, nas quatro edições do documento, como um continente sem graves conflitos de natureza interestatal e relativamente pacífica, tal como sintetizado no Quadro I.

\begin{tabular}{|c|l|}
\hline $\begin{array}{c}\text { Edição da PDN / } \\
\text { PND }\end{array}$ & \multicolumn{1}{|c|}{ Percepção Relativa à América do Sul } \\
\hline PDN r996 & "A América do Sul, distante dos focos mundiais de \\
(Seção 2.6) & $\begin{array}{l}\text { tensão, é considerada a região mais desmilitarizada } \\
\text { do mundo. [... Os Os contenciosos regionais têm sido } \\
\text { administrados em níveis toleráveis.” }\end{array}$ \\
\hline
\end{tabular}

6 A PND 2016 em seu item 4.I, aponta que os Objetivos Nacionais de Defesa “devem ser interpretados como as condições a serem alcançadas e mantidas permanentemente pela nação brasileira no âmbito de defesa" (Brasil 20ı6c).

7 Vide Brasil 2008, 2012a е 20I6а.

8 A PND 20I6, em seu segundo capítulo, subitem 2.I.6, delimita o entorno estratégico brasileiro da seguinte forma: "[...], sem desconsiderar a esfera global, estabelece como área de interesse prioritário o entorno estratégico brasileiro, que inclui a América do Sul, o Atlântico Sul, os países da costa ocidental africana e a Antártica (Brasil 20ı6c). 


\begin{tabular}{|c|l|}
\hline $\begin{array}{c}\text { PDN 2005 } \\
\text { (Seção 3.2) }\end{array}$ & $\begin{array}{l}\text { "A América do Sul, distante dos principais focos mundiais } \\
\text { de tensão e livre de armas nucleares, é considerada uma } \\
\text { região relativamente pacífica." } \\
\text { PND 20I2 }\end{array}$ \\
\hline Seção 4.2) & \\
PND 20I6 & "Noção 2.3.9 e âmbito regional, o período sem conflitos graves \\
2.3.IO) & e a convergência de interesses poderão contribuir \\
para o incremento da cooperação entre os países Sul- & $\begin{array}{l}\text { americanos [...]." } \\
\text { "Por outro lado, a América do Sul, o Atlântico Sul, } \\
\text { a Antártica e a África ocidental detêm significativas } \\
\text { reservas de recursos naturais, em um mundo já cioso } \\
\text { da escassez desses ativos. Tal cenário poderá intensificar } \\
\text { a ocorrência de conflitos nos quais prevaleça o uso da } \\
\text { força ou o seu respaldo para a imposição de sanções } \\
\text { políticas e econômicas, com eventual militarização do } \\
\text { Atlântico Sul, área cuja consolidação como Zona de Paz } \\
\text { e Cooperação revela-se fundamental para resguardá-la } \\
\text { da interferência de interesses não legítimos." }\end{array}$ \\
\hline
\end{tabular}

Quadro 1 - Percepções Relativas à América do Sul Expressas nas Três Primeiras Edições da PND.

Cabe observar quer a última atualização da PND (20I6) continua a apontar para a América do Sul, assim como para o Atlântico Sul como regiões estáveis, sem graves conflitos interestatais e com possibilidade de crescente cooperação regional. No entanto, o documento, de modo distinto das edições anteriores da PND, contém a ressalva de que essa situação de estabilidade pode ser rompida em decorrência de conflitos envolvendo o uso da força militar, originados pela disputa das significativas reservas de recursos naturais abundantes na região e escassos em outras partes do globo.

No que tange aos cenários internacionais e regionais apresentados nas edições da PDN 2005 e PND 2012 e 2016 vê-se que, a partir destes cenários, foram enunciados os Objetivos Nacionais de Defesa (OND) ${ }^{9}$. Nos três documentos, a estabilidade regional é identificada como um dos OND do Es-

9 Tal como já mencionado, a PND 20I6, em seu item 4.I, aponta que os Objetivos Nacionais de Defesa "devem ser interpretados como as condições a serem alcançadas e mantidas permanentemente pela nação brasileira no âmbito de defesa” (Brasil 20I6c).

116 Austral: Revista Brasileira de Estratégia e Relações Internacionais v.7, n.14, Jul./Dez. 2018 
tado brasileiro, tal como evidenciado no Quadro $2 .{ }^{\text {Io }}$

\begin{tabular}{|c|l|}
\hline $\begin{array}{c}\text { Edição da PDN / } \\
\text { PND }\end{array}$ & \multicolumn{1}{c|}{ Estabilidade Regional como OND } \\
\hline PDN 2005 & $\begin{array}{l}\text { "Assim, da avaliação dos ambientes descritos, emergem } \\
\text { objetivos da Defesa Nacional: [...] IV - a promoção da } \\
\text { estabilidade regional.” }\end{array}$ \\
\hline PDN 20I2 & $\begin{array}{l}\text { "Assim, da avaliação dos ambientes descritos, emergem } \\
\text { os Objetivos Nacionais de Defesa: [...] IV - contribuir } \\
\text { para a estabilidade regional." }\end{array}$ \\
\hline PDN 20I6 & $\begin{array}{l}\text { "São Objetivos Nacionais de Defesa:[...] V - Contribuir } \\
\text { para a estabilidade regional e para a paz e a segurança } \\
\text { internacionais." }\end{array}$ \\
\hline
\end{tabular}

Quadro 2 - Estabilidade Regional como OND.

Em síntese, a estabilidade regional faz parte da visão de defesa do Estado brasileiro para a América do Sul e para o Atlântico Sul. Nesse sentido, é pertinente observar como a Estratégia de Nacional de Defesa (END), estabelece estratégias, diretrizes e ações a empreender para a consecução deste Objetivo Nacional de Defesa.

Antes, porém, cabe apontar a percepção decorrente da pesquisa efetuada de que a END de 2008 não é um documento diretamente alinhado com a PDN de 2005 e, portanto, não apresenta Estratégias de Defesa e suas subsequentes Ações Estratégicas de Defesa, específicas para os Objetivos Nacionais de Defesa enunciados na PDN de 2005. Mesmo assim, sua Diretriz número I8, tem como tema a integração da América do Sul e a construção de uma identidade sul-americana como fatores que contribuiriam para a defesa do Estado brasileiro.

Diretrizes da Estratégia Nacional de Defesa.

[...].I8. Estimular a integração da América do Sul.

Essa integração não somente contribuirá para a defesa do Brasil, como pos-

Io A PDN de I996 não tem a estabilidade regional como um dos Objetivos de Defesa Nacional. No entanto, estabelece, como Diretriz:

"f. Contribuir ativamente para o fortalecimento, a expansão e a solidificação da integração regional;

g. Atuar na manutenção de um clima de paz e cooperação ao longo das fronteiras nacionais, e para a solidariedade na América Latina e na região do Atlântico Sul" (Brasil I996). 
sibilitará fomentar a cooperação militar regional e a integração das bases industriais de defesa. Afastará a sombra de conflitos dentro da região. Com todos os países avança-se rumo à construção da unidade sul-americana. $\mathrm{O}$ Conselho de Defesa Sul-Americano, em debate na região, criará mecanismo consultivo que permitirá prevenir conflitos e fomentar a cooperação militar regional e a integração das bases industriais de defesa, sem que dele participe país alheio à região. (Brasil 2008). (Grifo nosso).

A END atualizada em 2012 apresenta, em sua Diretriz número I8, praticamente o mesmo conteúdo do documento de 2008 , continuando a destacar a relevância da integração e da criação de uma identidade regional como parte do projeto de defesa do Estado brasileiro.

Um ponto a ser destacado é que tanto na END de 2008 quanto na de 20I2, a Diretriz supracitada explicita que o projeto de integração e construção de identidade exclui países exógenos à região.

Nesse sentido, a criação do Conselho de Defesa Sul-Americano (CDS), no âmbito da União de Nações Sul-Americanas (UNASUL), representou um marco significativo na consolidação da visão brasileira de defesa para a região. Cabe, portanto, uma breve remissão à criação desses dois órgãos.

A UNASUL teve seu Tratado constitutivo aprovado pelos representantes dos I2 Estados membros durante a Reunião Extraordinária de Chefes de Estado e de Governo, realizada em Brasília, em 23 de maio de 2008 (Brasil 20I2c).

O Tratado apresenta no seu artigo 3, os Objetivos Específicos da UNASUL que na alínea "s" prevê: "o intercâmbio de informação e de experiências em matéria de defesa."

Consoante com esse Objetivo Específico, os Estados membros da UNASUL criaram o Conselho de Defesa Sul-Americano (CDS), cujo Estatuto foi aprovado em 16 de dezembro de 2008 , durante a Cúpula Extraordinária da UNASUL realizada em Salvador. O Estatuto, em seu Artigo 4, define os Objetivos Gerais do CDS nos seguintes termos:

a) Consolidar Suramérica como una zona de paz [...].

b) Construir una identidad suramericana en materia de defensa, que tome en cuenta las características subregionales y nacionales y que contribuya al fortalecimiento de la unidad de América Latina y el Caribe. defensa. ${ }^{\text {II }}$

c) Generar consensos para fortalecer la cooperación regional en materia de

II UNASUR. Archivo Digital de UNASUR. "Estatuto Del Consejo de Defensa Suramericano

118 Austral: Revista Brasileira de Estratégia e Relações Internacionais v.7, n.14, Jul./Dez. 2018 
Feita essa breve remissão acerca da criação da UNASUL e do CDS, cabe observar o conteúdo da END revisada em 20ı6. Essa edição do documento configura-se como aquela de maior aderência à PND que lhe deu origem, isto é aquela revisada em 20I6. Isso decorre do alinhamento claro das Estratégias de Defesa (ED) apresentadas na END 20ı6, em relação aos Objetivos Nacionais de Defesa enunciados na PDN 20I6. Além disso, a END 2016 apresenta as Ações Estratégicas de Defesa (AED), decorrentes de cada Estratégia de Defesa, a fim de orientar as ações a empreender para a consecução dessa Estratégia e consequentemente do Objetivo Nacional de Defesa a alcançar.

Nesse sentido, para o Objetivo Nacional de Defesa número 5 (OND 5) - Contribuir para a Estabilidade Regional e para a Paz e a Segurança Internacionais - a END (20I6) apresenta três Estratégias de Defesa (ED) ${ }^{12}$, das quais destacamos a de número II, bem como as Ações Estratégicas de Defesa (AED) a empreender para sua consecução, sumarizadas no Quadro 3.

\begin{tabular}{|c|c|}
\hline Estratégias de Defesa (ED) & Ações Estratégicas de Defesa (AED) \\
\hline $\begin{array}{l}\text { ED-ıI Promoção da integração } \\
\text { regional } \\
\text { Trata-se das ações que visam à } \\
\text { consolidação de uma mentalidade } \\
\text { própria de defesa no âmbito } \\
\text { da América do Sul, buscando- } \\
\text { se incrementar o nível de } \\
\text { comprometimento dos países da } \\
\text { Região, nos esforços conjuntos para } \\
\text { solução de problemas comuns nesse } \\
\text { tema. (Grifo nosso) }\end{array}$ & $\begin{array}{l}\text { AED-44 - Estimular o } \\
\text { desenvolvimento de uma identidade } \\
\text { sul-americana de defesa. (Grifo } \\
\text { nosso). } \\
\text { AED-45 - Intensificar as parcerias } \\
\text { estratégicas, a cooperação e o } \\
\text { intercâmbio militar com as Forças } \\
\text { Armadas dos países da União das } \\
\text { Nações Sul-Americanas - UNASUL. } \\
\text { AED-46 - Incrementar a participação } \\
\text { brasileira no Conselho de Defesa } \\
\text { Sul-Americano - CDS/UNASUL. }\end{array}$ \\
\hline
\end{tabular}

Quadro 3 - Estratégias de Defesa (ED) e Ações Estratégicas de Defesa (AED) para a consecução do OND-5 “Contribuir para a Estabilidade Regional e para a Paz e a Segurança Internacionais".

\footnotetext{
de La UNASUR". Available at

<https://repo.unasursg.org/alfresco/service/unasursg/documents/content/ ESTATUTO_DEL_CONSEJO_DE_DEFENSA_SURAMERICANO_DE_LA_UNASUR. pdf?noderef=ddb8870e-73fa-4573-bdi2-eec3aaf67f55, accessed April 21, 20 I8.

I2 ED-II Promoção da integração regional; ED-I2 Promoção da cooperação internacional; e EDI3 Atuação em organismos internacionais (Brasil 20I6a).
} 
À luz dos documentos analisados é perceptível que os objetivos de defesa relativos à América e Atlântico Sul, expressos nas diversas edições da Política Nacional de Defesa, bem como as estratégias para alcançá-los, expressas com maior ou menor precisão e alinhamento nas edições da Estratégia Nacional de Defesa, permanecem constantes desde 1996.

Em síntese, pode-se inferir que a visão de defesa do Estado brasileiro para a América do Sul e para o Atlântico Sul, tem como objetivo a crescente integração e a manutenção da paz e da estabilidade dessa região, estando também associada à criação de uma "identidade sul-americana".

O projeto está inserido no contexto de que a sua consolidação impulsionará a autonomia e o desenvolvimento dos Estados da região, por meio da cooperação e de uma perspectiva própria, ancorada em uma convergência de fatores históricos, econômicos, sociais, políticos e militares. No conjunto, o efeito final desejado em termos de defesa é minimizar as possibilidades de conflitos militares interestatais no entorno estratégico brasileiro.

No entanto, tal projeto tem e terá que lidar com Estados exógenos à região que possuem territórios, continentais na América do sul e insulares, no Atlântico Sul. A França e o Reino Unido são os Estados que possuem esses territórios, nos quais estão presentes contingentes militares que já causam tensões na região, caso da Malvinas, como poderão gerar tensões futuras, caso da Guiana Francesa, conforme será discutido adiante.

\section{O Reino Unido e o Atlântico Sul}

Ao longo do século XIX, o Reino Unido construiu uma estratégica rede de possessões insulares no Atlântico Sul, por meio das ilhas de Ascensão, Santa Helena, Tristão da Cunha, Malvinas, Geórgia do Sul e Sandwich do Sul. Destas ilhas, as três últimas são objeto de disputa de soberania com a Argentina, sendo o principal foco de tensão político-militar interestatal na região.

As ilhas Malvinas, Geórgia do Sul e Sandwich do Sul eram parte das possessões coloniais espanholas e são reivindicadas pela Argentina, desde a sua independência em I8I6. No entanto, os britânicos dominaram e colonizaram as ilhas Malvinas desde 1833 .

Em abril de I982, o governo argentino, então uma ditadura militar, invadiu e ocupou militarmente as ilhas, desencadeando a reação militar britânica e o conflito conhecido como Guerra das Malvinas. Após 73 dias de conflito militar (2 de abril a I4 de junho de I982), as ilhas voltaram ao domínio 
britânico.

Cabe uma breve remissão ao apoio que o Reino Unido recebeu, direta ou indiretamente, de alguns Estados da Organização do Tratado do Atlântico Norte (OTAN), podendo ser destacados os seguintes eventos:

- o governo de Portugal se mostrou disposto a autorizar a utilização da base de Lajes, nos Açores, caso o governo do Reino Unido assim solicitasse (Anguera, Ayuso, Toledo I985, 44);

- os Estados Unidos autorizaram a utilização do seu aeródromo na ilha de Ascensão, bem como forneceram mísseis Ar-Ar Sidewinder (AIM-9L) ${ }^{13}$ para as aeronaves Harrier e Sea Harrier britânicas, mesmo antes de declarar seu apoio irrestrito ao Reino Unido (Woodward I997, xviii, 82, 87 e i26); e

- o governo francês embargou a entrega dos mísseis Ar-Superfície AM-39 Exocet comprados pela Argentina ${ }^{\mathrm{I4}}$ (Woodward 1997, 224).

Em síntese, o apoio prestado por parte de alguns membros da OTAN foi decisivo para viabilizar a campanha militar do Reino Unido, durante a Guerra das Malvinas.

Nos anos subsequentes ao término da Guerra das Malvinas, os dois Estados iniciaram uma lenta reaproximação e normalização das relações diplomáticas. No entanto, as relações entre os governos da Argentina e do Reino Unido passam por períodos recorrentes de tensões políticas. Os governos de Nestor e Cristina Kirchner protagonizaram várias delas. Porém, as mais recentes foram decorrentes das iniciativas britânicas para exploração de hidrocarbonetos na Zona Econômica Exclusiva associada às ilhas. É também pertinente recordar que em 20I2, com o aniversário dos 30 anos do conflito de I982, os dois Estados iniciaram uma ofensiva diplomática defendendo seus respectivos direitos de soberania nas ilhas.

Nesse contexto, mesmo com as tensões recorrentes produzidas tanto pelo presidente Nestor Kirchner quanto por sua sucessora Cristina Kirchner, a diplomacia brasileira apoiou, de forma clara, a reivindicação de soberania argentina, mas manteve a prudente postura de não se envolver em nenhuma crise decorrente das posições assumidas pelo governo argentino. Um exem-

I3 Esses mísseis, então de última geração, foram decisivos nos engajamentos das aeronaves britânicas contra as aeronaves de ataque argentinas, uma vez que seus novos sensores infravermelhos permitiam o seu lançamento, sem a necessidade de se posicionar atrás da aeronave alvo, possibilitando uma vantagem tática ao seu utilizador (Nota do autor).

I4 Cabe recordar que os cinco mísseis Exocet AM-39, que já haviam sido recebidos pela Marinha da Argentina, foram utilizados ao longo do conflito e resultaram no afundamento da HMS Sheffield e do Atlantic Conveyor (Nota do autor). 
plo dessa postura ocorreu em 20II, quando o Itamaraty negou permissão para que o navio de patrulha oceânico HMS Clyde, que opera nas Malvinas, fosse reabastecido em portos brasileiros. No entanto, de acordo com as notícias publicadas na mídia brasileira ${ }^{15}$, argentina ${ }^{16}$ e britânica ${ }^{17}$, a chancelaria brasileira esclareceu que a permissão para que navios do Reino Unido pudessem atracar em portos brasileiros seria analisada caso a caso. Em outras palavras, foi esclarecido que não havia uma determinação para que a decisão relativa ao HMS Clyde fosse estendida a todos os navios da Royal Navy que operassem nas Malvinas. O evento não teve maiores repercussões junto ao governo britânico e um porta-voz do Foreign Office comunicou que governo britânico respeitava a decisão brasileira e os dois países continuavam a ter relações positivas.

Em síntese, para o governo britânico as Malvinas são as Falkland Islands e têm o status de "overseas territory", sendo parte do Reino Unido e, portanto, protegidas pelas forças armadas daquele Estado. ${ }^{18}$ É neste contexto que se inserem as British Forces South Atlantic Islands, um comando conjunto com contingentes do exército, marinha e força aérea. Após a Guerra das Malvinas (abril - junho de I982), sucessivos governos britânicos investiram no aparato defensivo das ilhas, incluindo a construção de uma Base aérea - RAF Mount Pleasant - a cerca de $40 \mathrm{~km}$ a oeste de Port Stanley, a qual está operacional desde $1985 .{ }^{\text {I9 }}$

I5 Folha de São Paulo. "Em apoio à Argentina, Brasil barra embarcação britânica” (I2 de janeiro de 20I2), Available at http://wwwi.folha.uol.com.br/fsp/mundo/ftı2OI20IIo2.htm, accessed April 30, 2018.

I6 La Nacion. "Confirman que negaron el ingreso a un buque inglés” (I3 de enero de 20II), Available ar http://www.lanacion.com.ar/I34IO22-confirman-que-negaron-el-ingreso-a-unbuque-ingles, accessed April 30, 2018

I7 The Telegraph. "Royal Navy's Falklands ship turned away by Brazil” (ıо Jan 20II), Availabel at http://www.telegraph.co.uk/news/worldnews/southamerica/falklandislands/825II30/ Royal-Navys-Falklands-ship-turned-away-by-Brazil.html, accessed April 30, 2018.

I8 A página do governo britânico intitulada British forces overseas: Falkland Islands and Ascension Island apresenta a seguinte explicação para a presença militar britânica naquelas ilhas: "Forces are based in the Falklands to demonstrate the government's continued commitment to the security of UK overseas territories in the south Atlantic. They include air defence assets, maritime patrol capability and infantry forces. There are also regular naval deployments to the region and temporary deployments for routine exercises. The exact force levels are kept under constant review and are structured and maintained at a level consistent with this policy." (United Kingdon.Gov.UK. "British forces overseas: Falkland Islands and Ascension Island," Available at https://www.gov.uk/guidance/british-forces-overseas-falkland-islands-andascension-island, accessed April 22, 2018.

I9 United Kingdon.Gov.UK. "Mount Pleasant Defence Aerodrome Manual 20I7,"

Disponível em https://www.gov.uk/government/uploads/system/uploads/attachment_data/ file/657078/20170427-Mount_Pleasant_DAM_Vi.o.pdf, accessed April 22, 2018.

122 Austral: Revista Brasileira de Estratégia e Relações Internacionais v.7, n.14, Jul./Dez. 2018 
A Royal Air Force (RAF) mantém permanentemente desdobradas naquela base, quatro aeronaves Eurofighter Typhoon, uma aeronave de transporte C-izo e uma aeronave VC-ıo para reabastecimento em voo. Baterias de Mísseis Superfície-Ar (MSA) Rapier estão posicionadas pelas duas ilhas principais e o contingente militar britânico nas ilhas oscila em torno de I.200 homens. ${ }^{20}$

A base aérea Wideawake, torna a ilha de Ascensão um ponto de apoio logístico valioso para as forças militares britânicas desdobradas no Atlântico Sul. Em conjunção com a base aérea de Mount Pleasant, o Reino Unido tem condições de reforçar militarmente as Malvinas ao menor sinal de movimentação ou hostilidade por parte de uma eventual força militar argentina. ${ }^{2 \mathrm{~T}}$

A Royal Navy mantém um navio de patrulha, um navio de apoio logístico e uma fragata ou contratorpedeiro permanentemente em patrulha na região. Ocasionalmente, surgem notícias na imprensa britânica que um submarino nuclear (SSN) é mantido também em patrulha no Atlântico Sul ${ }^{22}$. Mesmo sem este último meio, o aparato militar mantido na região para defesa das ilhas é significativo e, certamente, age como um elemento de dissuasão quanto a qualquer pretensão argentina de uma nova tentativa de retomar as ilhas pela força militar.

O Ministério de Relações Exteriores do Reino Unido expressa, em diversos e recorrentes comunicados, que a razão da presença militar britânica nas ilhas visa a respeitar e garantir a autodeterminação dos seus habitantes que desejam permanecer cidadãos britânicos. Esse compromisso foi mais uma vez reiterado na mensagem do Foreign Office Minister - Sir Allan Duncan - relativa ao $35^{\circ}$ aniversário do término do conflito militar de I982. Disse o ministro: "Continuamos comprometidos e empenhados em defender o direito dos habitantes das Falkland de determinar seu próprio futuro e de permanecer britânicos, de acordo com seus desejos. ${ }^{23}$ (Tradução nossa).

20 As seguintes fontes permitiram uma compilação básica das presença militar britânica nas Malvinas: United Kingdon. Royal Air Force (RAF). RAF Mount Pleasant. "The Station”. Available at , https://www.raf.mod.uk/our-organisation/stations/raf-mount-pleasant/, accessed April 2I, 20I8; - BBC. "Britain to boost Falklands Islands defences," Available at http://www.bbc.com/ news/uk-politics-32031342, Accessed April 21, 2018; BBC. "Where are British troops deployed overseas?” Available at http://www.bbc.com/news/uk-349I9954, accessed April 2I, 2018.

2I United Kingdon. Royal Air Force (RAF). "RAF Ascension Island”. Available at, https:// www.raf.mod.uk/our-organisation/stations/raf-ascension-island/, acessado em June 8, 2018.

22 Daily Mail Online. "British nuclear submarine sent to Falklands in show of strength as tensions rise ahead of zoth anniversary of conflict". Available at http://www.dailymail.co.uk/ news/article-2I47045/Sub-way-Falklands.html, Accessed April 2I, 2018.

23 "We remain committed to upholding the right of the Falkland Islanders to determine their own future, and to remain British in line with their wishes" (United Kingdom.Gov. UK.gov.uk. Press release published I4 June 20I7. "Foreign Office Minister Statement on the 
É pertinente recordar que nos dias io e II de março de 2013 , foi realizado um referendo entre os habitantes das ilhas, para que se manifestassem quanto a continuidade ou alteração do status de "British Overseas Territory". De um eleitorado de I.653 pessoas, I.5I7 exerceram seu direito de voto e apenas três votaram contra a manutenção do atual status. Em outras palavras, 99,8\% dos votos foram favoráveis à manutenção das ilhas como parte do Reino Unido. $^{24}$

Assim sendo, para o governo britânico a presença militar nas ilhas é um compromisso com a segurança e defesa dos habitantes das ilhas, decorrente da autodeterminação daquelas pessoas que, de forma legítima e democrática, optaram por permanecer com o status de British Overseas Territory. ${ }^{25}$

O custo para a manutenção desse aparato militar nas ilhas Malvinas corresponde a aproximadamente $0.5 \%$ do orçamento de defesa do Reino Unido. ${ }^{26}$ Uma relação "custo x benefício" vantajosa sob quaisquer aspectos, haja vista que as ilhas apresentam uma indústria pesqueira lucrativa, além de reservas de hidrocarbonetos significativas em sua Zona Econômica Exclusiva. Adicionalmente, constituem uma importante posição em relação ao continente antártico, tanto no presente quanto em futuras negociações envolvendo aquela região.

À luz do exposto, percebe-se que a presença militar britânica no Atlântico Sul é expressiva e, principalmente, fundamentada em interesses econômicos, políticos e estratégicos, não configurando a possibilidade de alteração desse status quo em uma moldura temporal de curto e médio prazo. Nesse contexto, as crises escaladas pelos dois Estados envolvidos, notadamente, aquelas eventualmente protagonizadas pela Argentina em relação à soberania das ilhas e/ou exploração da zona econômica exclusiva, podem levar a maior presença militar do Reino Unido na região. No limite, um ativo programa de modernização das Forças Armadas argentinas, associado a discursos de recu-

35th anniversary of end of the Falkland Islands conflict," Available at https://www.gov.uk/ government/news/foreign-office-minister-statement-on-the-35th-anniversary-of-end-of-thefalkland-islands-conflict, accessed April 29, 20I8).

24 Falkland Islands Government. "Results of the referendum on the Political Status of the Falkland Islands". Available at https://www.falklands.gov.fk/results-of-the-referendum-on-thepolitical-status-of-the-falkland-islands/, accessed April 22, 2018.

25 United Kingdom.Gov.UK. Policy. "Falkland Islanders' right to self-determination"

Disponível emhttps://www.gov.uk/government/policies/supporting-the-falkland-islandersright-to-self-determination, acesso em 22 de abril de 2018.

26 United Kingdom.Gov.UK. Policy Paper. "2010 to 2015 government policy: Falkland Islanders' right to self-determination". Available at https://www.gov.uk/government/publications/2oroto-20I5-government-policy-falkland-islanders-right-to-self-determination/2010-to-20I5government-policy-falkland-islanders-right-to-self-determination, accessed April 22, 2018.

124 Austral: Revista Brasileira de Estratégia e Relações Internacionais v.7, n.14, Jul./Dez. 2018 
peração das ilhas, pode levar a uma resposta similar do Reino Unido, implicando em uma militarização do Atlântico Sul e em instabilidade no cone sul do continente sul-americano. Tal cenário estaria frontalmente em desacordo com a visão de defesa brasileira para a região.

A questão das Malvinas é um caso singular para a política externa brasileira, uma vez que o Estado brasileiro apoia as reivindicações argentinas quanto à soberania sobre as ilhas, porém tem como princípio constitucional regulador da sua política externa a autodeterminação dos povos. ${ }^{27} \mathrm{~A}$ situação coloca um dilema potencial para a política externa brasileira, pois, refutar apoio a uma reivindicação de soberania do seu maior vizinho e parceiro econômico regional comprometeria o OND de manter a estabilidade na região, bem como as Estratégias de Defesa relativas ao projeto de integração regional e de criação de uma mentalidade sul-americana e sul-atlântica sem Estados exógenos à região. Por outro lado, o princípio constitucional supracitado, bem como os fortes laços econômicos com o Reino Unido, permitem apontar que a manutenção do status quo é o que, no momento, menos prejudica a visão de defesa do Estado brasileiro para o Atlântico Sul.

\section{A França na América do Sul}

A França é outro Estado europeu presente na América do Sul, em uma privilegiada posição tanto no continente quanto no Atlântico Sul, por meio da posse da Guiana Francesa. Esse território, com uma área de aproximadamente $86.000 \mathrm{~km}^{2}$ e com uma população de aproximadamente 260.000 habitantes ${ }^{28}$, tem o status de Departamento Ultramarino (département d'outre$-m e r)^{29}$. Sua localização estratégica, próxima à linha do Equador, proporcionou à França a construção de uma base de lançamento de foguetes extremamente rentável, além do acesso aos recursos naturais existentes na região.

A proximidade da Guina Francesa em relação à linha do Equador possibilitou que a França iniciasse, em I964, a construção do Centro Espacial de Kourou (Centre Spatial Guyanais - CSG), localizado a aproximadamente 500 quilômetros ao norte da linha do Equador. Essa posição permite a utilização de veículos lançadores de satélites de forma economicamente competitiva,

27 Artigo 4, inciso III, da Constituição Federal de I988 (Brasil I988).

28 França. Institut national de la statistique et des études économiques (INSEE). "Recensement de la population en Guyane." Available at https://www.insee.fr/fr/statistiques/3309060, accessed April 28, 2018.

29 Collectivite Territoriale de Guyane. "Guyane française: situation géographique.” Available at http://www.axl.cefan.ulaval.ca/amsudant/guyanefr..htm, accessed April 29, 20 I8. 
haja vista que quanto mais próximo da linha do Equador menos combustível é requerido (para uma mesma massa a ser transportada) para que um foguete saia da atmosfera terrestre. A Agência Espacial Europeia é a principal cliente do CSG, mas outros usuários também pagam para utilizar as instalações do Centro. A Ucrânia, a Rússia, o Japão e a China já efetuaram lançamentos de seus respectivos foguetes Zénith, Soyuz, $\mathrm{H} 2$ e Longa Marcha. ${ }^{3 \circ}$

O Brasil é, também, um cliente do CSG. Em maio de 2017 foi lançado o primeiro satélite geoestacionário brasileiro, destinado a comunicações, incluindo aquelas da área de defesa. O satélite foi lançado do CSG por um foguete Ariene 5 e posicionado, em órbita geoestacionária, a uma distância de aproximadamente 36.000 quilômetros da superfície da Terra. ${ }^{3}$

O CSG materializa a capacidade francesa de efetuar lançamentos de foguetes para fins científicos e comerciais próprios. Além disso, proporciona à França uma excelente fonte de recursos, decorrentes da colocação de satélites em órbita para outros Estados, utilizando os veículos lançadores da série Ariane, ou da locação temporária das instalações para o lançamento de foguetes de outros Estados detentores desses meios. Esses fatores conferem à Guiana Francesa, uma importância singular em termos políticos, estratégicos e econômicos. Essa percepção está presente no conteúdo do mais recente Livro Branco de Defesa da França, cuja edição é de 2013 e apresenta a seguinte percepção em relação à Guiana Francesa:

A área Antilhas - Guiana é uma encruzilhada onde se expressam múltiplas influências. Os Estados Unidos estão muito presentes, mas também os países da América Central e do Sul (Brasil, México, Venezuela...) e alguns países europeus que retêm interesses na região (Espanha, Holanda, Reino Unido). Esta área representa um desafio estratégico não só para a França, mas para a Europa, em função da localização do Centro Espacial de Kourou na Guiana. É também uma área de incerteza significativa que viu o crescimento do tráfico ilícito transnacional: drogas (a região é a fonte de metade da produção mundial de cocaína), lavagem de dinheiro, mineração, imigração e pesca ilegal etc [...]. Além disso, o risco de desastres naturais é particularmente elevado no Caribe. Finalmente, a presença de muitos cidadãos

30 França. Centre Spatial Guyanais. "Politique Spatiale," Available at http://www.cnes-csg.fr/ web/CNES-CSG-fr/9778-politique-spatiale.php, accessed April 29, 2018.

3I O satélite opera nas bandas de comunicações $X$ e Ka, sendo a primeira destinada ao uso por parte do Ministério da defesa, correspondendo a cerca de $30 \%$ da capacidade do satélite (Empresa Brasil de Comunicação - EBC. "Lançado ao espaço satélite brasileiro que será usado para comunicações e defesa," Available at http://agenciabrasil.ebc.com.br/pesquisa-einovacao/noticia/20I7-05/lancado-ao-espaco-satelite-brasileiro-que-sera-usado-para, Accessed April 29, 2018).

\section{Austral: Revista Brasileira de Estratégia e Relações Internacionais} v.7, n.14, Jul./Dez. 2018 
franceses e europeus, nos países vizinhos, reforça a necessidade da França ser capaz de posicionar, rapidamente, meios de evacuação e de segurança. Portanto, além das questões de soberania e proteção da população francesa vivendo nestes territórios, a França deve assumir as responsabilidades inerentes à sua presença nesta complexa região ${ }^{32}$ (França 2013, 50) (Tradução e Grifo nosso).

Consonante com a percepção expressa de forma clara no seu Livro Branco de Defesa, a França mantém na Guiana Francesa uma presença militar constituída por unidades e meios das três forças singulares. Esse efetivo perfaz um total de aproximadamente 2.I00 militares. ${ }^{33}$

A Marinha francesa se faz presente por meio de dois navios-patrulha da classe P400, e duas embarcações da Gendarmerie Maritime operam a partir da base naval de Dégrad-des-Cannes, localizada próxima a Cayenne. ${ }^{34}$ As principais tarefas da Marinha da França estão voltadas para a fiscalização do mar territorial e águas jurisdicionais, enfocando o combate à pesca ilegal,35 além da proteção marítima do CSG. ${ }^{36}$

32 La zone Antilles-Guyane est un carrefour où s'expriment de multiples influences. Les ÉtatsUnis y sont très présents, mais aussi les pays d'Amérique centrale et du Sud (Brésil, Mexique, Venezuela...) et certains pays européens qui y conservent des intérêts (Espagne, Pays-Bas, Royaume-Uni ). Cette zone représente um enjeu stratégique non seulement pour la France, mais aussi pour l'Europe, du fait de l'implantation en Guyane du centre spatial de Kourou. Il s'agit également d'une zone d'insécurité importante qui voit se développer de très nombreux trafics illicites transnationaux : drogue (la région est à l'origine de la moitié de la production mondiale de cocaïne), orpaillage illégal, blanchiment d'argent, immigration clandestine, pêche illégale, etc [...]. Par ailleurs, le risque de catastrophes naturelles est particulièrement élevé aux Antilles. Enfin, la présence de nombreux ressortissants français et européens dans les pays voisins renforce le besoin de pouvoir y mettre rapidement en oeuvre des moyens d'évacuation ou de sécurisation. Dès lors, au delà des enjeux de souveraineté et de protection de la population française vivant sur ces territoires, la France se doit d'assumer les responsabilités que lui confère sa présence dans cette région complexe (França 2013, 50).

33 França. Ministère des Armées. "Les Forces Armées en Guyane," Available at http://www. defense.gouv.fr/ema/forces-prepositionnees/guyane/dossier/les-forces-armees-en-guyane, accessed April 23, 2018.

34 França. Marine Nationale. "La Marine en Guyane," Available at http://www.defense.gouv. $\mathrm{fr} /$ marine/operations/zoom-sur-la-marine-en-outre-mer/annee-de-l-outre-mer-la-marine-enguyane/la-marine-en-guyane, accessed April 22, 2018.

35 Em 20I6, a ação da Marinha francesa contra a pesca ilegal na Guiana Francesa resultou na apreensão de 35 embarcações e cerca de $270 \mathrm{~km}$ de redes, além de iıo toneladas de pescado (Brasil. Ministério da Defesa. "Brasil e França discutem possibilidades de novas ações de cooperação transfronteiriças," Available at http://defesa.gov.br/noticias/30245-brasil-e-guianafrancesa-discutem-possibilidades-de-novas-acoes-nas-fronteiras, accessed April 29, 2018.

36 França. Marine Nationale. La Marine en Guyane. "Trois missions essentielles pour la Marine en Guyane," Available at http://www.defense.gouv.fr/marine/operations/zoom-sur-la-ma- 
A força terrestre é constituída por dois regimentos: o $9^{e}$ Régiment d'infanterie de marine ( $\left.9^{\mathrm{e}} \mathrm{RIMa}\right)$ e o $3^{e}$ Régiment étranger d'infanterie $\left(3^{\circ} \mathrm{REI}\right)$.

$\mathrm{O} 9^{e}$ Régiment d'infanterie de marine ( $9^{\mathrm{e}} \mathrm{RIMa}$ ), sediado em Cayenne, tem como missões: "atuar em proveito do Estado-Maior Conjunto (EMIA) e das forças terrestres na Guiana; e garantir o exercício da soberania francesa sobre a metade ocidental do departamento [...]”37 (Tradução nossa).

$\mathrm{O} 3^{e}$ Régiment étranger d'infanterie $\left(3^{\circ} \mathrm{REI}\right)$ tem como principais missões a proteção do CSG e o combate a mineração ilegal na Guiana Francesa ${ }^{38}$. É interessante observar que até janeiro de $20 \mathrm{I} 8$, na página oficial desta unidade militar, onde são apresentadas as missões supracitadas, constava também que: "O $3^{\circ} \mathrm{REI}$ é uma Força Operacional Pré-posicionada, capaz de intervir a qualquer momento na região da América do Sul e Caribe, como foi o caso em 2004, quando foi desencadeada a operação Carbet no Haiti"39 (Tradução nossa).

A Força Aérea opera a partir da Base Aérea 367 - Capitaine François Massé - localizada junto ao aeroporto internacional Félix Eboué. O Esquadrão de Transporte 68 está sediado nessa base aérea, tendo como meios três aeronaves CASA CN 235, cinco helicópteros Puma e quatro helicópteros Fennec. Além disso, a Força Aérea opera a estação Radar Mont de Venus..$^{\circ}$

De acordo com Ministério da Defesa da França, as forças militares

rine-en-outre-mer/annee-de-l-outre-mer-la-marine-en-guyane/trois-missions-essentielles-pour-la-marine-en-guyane, accessed April 22, 2018.

37 Le ge RIMa, dont le PC est basé à Cayenne, assure une double mission : un soutien au profit de l'état-major interarmées (EMIA) et des forces terrestres en Guyane, et une mission de souveraineté sur la moitié ouest du département [...]. (França. Armée de Terre. "9e régiment d'infanterie de marine," Available at https://www.recrutement.terre.defense.gouv. fr/regiments/ge-regiment-dinfanterie-de-marine, accessed April 22, 2018).

38 A mineração ilegal, principalmente a extração e o contrabando de ouro na região é um problema que vem sendo enfrentado de forma ativa por parte do efetivo terrestre das forças armadas na Guiana Francesa. Em 20I6, por exemplo, a Operação Harpie, que reprime este tipo de ilícito, apreendeu cerca de 6 toneladas de ouro (Brasil. Ministério da Defesa. "Brasil e França discutem possibilidades de novas ações de cooperação transfronteiriças. Disponível em http://defesa.gov.br/noticias/30245-brasil-e-guiana-francesa-discutem-possibilidades-denovas-acoes-nas-fronteiras, accessed April 29, 2018).

39 Le ze REI est une force opérationnelle prépositionnée. Il est en mesure d'intervenir à tout moment dans la zone Caraïbes-Amérique du Sud, comme ce fut le cas en 2004, lors de l'opération Carbet, en Haïti (França. ze Régiment étranger d'infanterie. "Les missions du ze régiment étranger d'infanterie,” Available at http://www.legion-etrangere.com/mdl/info_seul. php?id=463, accessed January 22, 2018).

40 França. Ministère des Armées. "Les Forces Armées en Guyane," Available at http://www. defense.gouv.fr/ema/forces-prepositionnees/guyane/dossier/les-forces-armees-en-guyane, accessed April 23, 2018.

128 Austral: Revista Brasileira de Estratégia e Relações Internacionais v.7, n.14, Jul./Dez. 2018 
presentes na Guiana têm como propósito "contribuir para o exercício da soberania francesa e a preservação dos interesses da França nesta região". ${ }^{\mathrm{I}}$ Nesse sentido, a França busca uma cooperação crescente com o Brasil, principalmente, nas ações voltadas para fazer frente à mineração e pesca ilegal na Guiana Francesa. Em abril de 20I7, por exemplo, o Comandante das Forças Armadas francesas na Guiana, major-brigadeiro Pierre-Jean Dupont, esteve em visita oficial ao Ministério da Defesa (MD) para discutir possibilidades de ampliar a cooperação militar na região de fronteira..$^{2}$

O interesse francês em maior cooperação entre as forças armadas dos dois países, nas ações contra os crimes transfronteiriços, ocorre em um momento em que o Exército brasileiro amplia sua presença no Amapá. A criação da $22^{a}$ Brigada de Infantaria de Selva, com o comando em Macapá, reflete a prioridade conferida pelo Estado brasileiro àquela região de fronteira e a maior cooperação militar naquela região poderá ser benéfica para os dois países. 43

Em síntese, com base na análise do efetivo e composição das forças presentes na Guiana Francesa, fica patente que a presença militar da França na região se destina prioritariamente à defesa do seu departamento ultramarino. No entanto, a existência de uma colônia europeia, em pleno século XXI, com presença militar terrestre, aérea e naval, parece não ser observada com desconforto pelos Estados sul-americanos.

Um ponto pertinente em relação à Guina Francesa e seu status de departamento ultramarino da França refere-se à questão da autonomia e eventualmente independência. Ainda que incipiente, existe um movimento político que defende a independência da Guiana. ${ }^{44}$ Como forma de demonstrar

4I O texto original diz: "Les FAG font partie des forces de souveraineté françaises basées sur les territoires d'outremer. A ce titre, elles contribuent à l'exercice de la souveraineté française et à la préservation des intérêts de la France dans cette région" (Ibid).

42 Brasil. Ministério da Defesa. "Brasil e França discutem possibilidades de novas ações de cooperação transfronteiriças," Available at http://defesa.gov.br/noticias/30245-brasil-e-guianafrancesa-discutem-possibilidades-de-novas-acoes-nas-fronteiras, Accessed April 29, 2018.

43 A Brigada está subordinada ao Comando Militar do Norte sendo constituída integrada pela Companhia de Comando da 22ffi Brigada de Infantaria de Selva; pelo Comando Fronteira Amapá/34ffl Batalhão de Infantaria de Selva, ambos em Macapá; pelo $2^{\circ}$ Batalhão de Infantaria de Selva, em Belém, no Pará; e pelo $24^{\circ}$ Batalhão de Infantaria de Selva, em São Luís, no Maranhão (Brasil. Ministério da Defesa. Exército Brasileiro. Noticiário do Exército, 26 de janeiro de 20I8. "Com a inauguração da Brigada da Foz do Amazonas, a presença do Exército Brasileiro na região é reforçada," Available at http://www.eb.mil.br/web/noticias/noticiario-doexercito/-/asset_publisher/MjaG93KcunQI/content/id/8569649, Accessed April 29, 20I8.).

44 Vide, por exemplo, as seguintes referências que apontam para esse movimento: Fontes, Yuri Martins. "Guiana-Caiena se insurge contra exploração colonial francesa," Available at https:// alemdarena.blogspot.com/20I7/03/guiana-caiena-se-insurge-contra.html, accessed April 29, 
que não é uma metrópole colonial no sentido clássico da palavra, em 20ıo, a França promoveu, pela primeira vez na Guiana Francesa, um referendo para verificar se a população desejava maior autonomia política e administrativa.

No referendo em pauta, realizado em io de janeiro de 20I0, os eleitores da Guiana Francesa foram consultados a responder "Sim" ou "Não" à seguinte pergunta: "Você concorda com a transformação da Guiana em uma comunidade ultramarina regida pelo artigo 74 da Constituição, com uma organização particular que leve em conta os seus próprios interesses na República?"45 (França 2009) (Tradução nossa).

Os resultados oficiais do referendo computaram uma participação de $48,16 \%$ do eleitorado com 70,22 \% dos votos respondendo "Não", isto é, recusando maior autonomia administrativa e política. ${ }^{46}$

O ponto a ser destacado é que, de fato, existe um movimento, ainda minoritário, em prol de uma maior autonomia em relação à França. Se no futuro, esse movimento ganhar corpo, o Brasil será instado a se posicionar, apoiando esse eventual movimento ou sendo solidário aos possíveis interesses contrários a essa autonomia por parte da França.

Cabe aqui recordar que, na primeira década do século XXI, a França se tornou o principal parceiro estratégico brasileiro na área de defesa. Porém, tal como já mencionado, nossa política externa é constitucionalmente regulada para o apoio à autodeterminação dos povos. Assim, a eventual concretização desse cenário de um movimento por maior autonomia na Guiana Francesa pode se configurar como um foco de potencial problema futuro com a França. No limite, uma oposição ou negativa da metrópole a maior autonomia da Guiana Francesa poderá resultar em um conflito local com desdobramentos sobre a visão de defesa brasileira para a América do Sul, haja vista que poderá ser uma fonte de instabilidade em parte do continente sul-americano, o que contraria o já analisado OND, contido nas edições de 2005, 2012 e 2016 da PND, relativo à paz e à estabilidade regional.47

20I8; BBC. "French Guiana: The part of South America facing a total shutdown". (Io April 20I7). Available at <http://www.bbc.com/news/world-europe-39557670, Accessed April 29, 2018.

45 "Approuvez-vous la transformation de la Guyane en une collectivité d'outre-mer régie par l'article 74 de la Constitution, dotée d'une organisation particulière tenant compte de ses intérêts propres au sein de la République?” (França 2009).

46 França Sénat. "Projet de loi relatif aux collectivités de Guyane et de Martinique." Available at http://www.senat.fr/rap/lio-467/lio-4677.html, accessed April 23, 2018.

47 Vide Quadro 2 (Nota do autor).

130 Austral: Revista Brasileira de Estratégia e Relações Internacionais v.7, n.14, Jul./Dez. 2018 


\section{Considerações finais}

A pesquisa realizada se insere no campo dos estudos de segurança internacional e regional, dentro de uma perspectiva brasileira..$^{8} \mathrm{O}$ objetivo, tal como exposto na Introdução, consistiu em evidenciar a presença militar da França e do Reino Unido na América e Atlântico Sul e analisar as tensões decorrentes dessa presença, em relação à visão brasileira de defesa para a região.

O ponto de partida foi identificar e destacar que o Estado brasileiro possui uma visão de defesa para a América do Sul e para o Atlântico Sul. Essa visão, que exclui a participação de atores exógenos à região, está consubstanciada nos principais documentos afetos aos temas de defesa emanados do poder executivo, e aprovados pelo legislativo brasileiro: a Política Nacional de Defesa; e a Estratégia Nacional de Defesa.

Com base na análise das edições da PDN / PND e da END foi possível inferir que a visão de defesa do Estado brasileiro, para a América do Sul e para o Atlântico Sul, tem como objetivos a manutenção da paz e da estabilidade regional, bem como a sua integração na área de defesa, estando também associada à criação de uma identidade sul-americana.

O projeto decorrente dessa visão de defesa está inserido na percepção de que a cooperação impulsionará a segurança, autonomia e o desenvolvimento dos Estados da região. No conjunto, o estado final desejado em termos de defesa é minimizar as possibilidades de conflitos militares interestatais no entorno estratégico brasileiro.

No entanto, esse projeto tem e terá que lidar com Estados exógenos à região que possuem territórios, continentais na América do sul e insulares, no Atlântico Sul. França e Reino Unido são Estados que possuem esses territórios, nos quais estão presentes contingentes militares que já causam tensões na região, caso da Malvinas, como poderão gerar tensões futuras, caso da Guiana Francesa.

A Guina Francesa é um enclave colonial no continente sul-americano, onde a França mantém um contingente militar, principalmente terrestre, capaz de ser projetado em intervenções pontuais tanto no Caribe quanto na América do Sul. A presença do Centro Espacial em Kourou confere ainda mais valor político, econômico e estratégico a Guiana Francesa, tal como apontado no Livro Branco de Defesa da França.

48 A coletânea publicada pela FGV, intitulada Segurança Internacional: Perspectivas Brasileiras (Alsina, Etchegoyen, Jobim 20I0) é um exemplo de textos produzidos por acadêmicos, militares e diplomatas brasileiros e voltados para o campo da segurança internacional e regional (Nota do autor). 
A possibilidade de que um movimento em prol de maior autonomia e até mesmo de independência da Guiana Francesa em relação a sua metrópole colonial é um cenário que não pode ser ignorado em análises prospectivas. Essa possibilidade, caso se concretize, configura-se como um futuro desafio para a visão brasileira de defesa regional, pois o Estado brasileiro tem como princípio constitucional regulador da sua política externa a autodeterminação dos povos e poderá ver-se na posição de ter de escolher entre o apoio a um movimento dessa natureza e o apoio aos interesses da França, país que, hoje, é um dos principais parceiros do Brasil na área de defesa.

Já a presença britânica nas Malvinas desponta como um potencial caso de conflito militar interestatal na região, envolvendo o Reino Unido e a Argentina. Conforme exposto, o Estado brasileiro apoia as reivindicações de soberania argentinas sobre as ilhas, porém existe, também, o princípio constitucional regulador da política externa brasileira relacionado à autodeterminação dos povos. Neste caso, os habitantes das Malvinas expressaram, de forma clara, o desejo de continuar sendo cidadãos britânicos. A situação coloca um dilema potencial para a política externa brasileira, pois refutar apoio a uma justa reivindicação de soberania do seu maior vizinho e parceiro econômico sul-americano comprometeria o projeto de integração regional e de criação de uma mentalidade sul-americana sem Estados exógenos à região. Por outro lado, o princípio constitucional supracitado, impede uma posição mais assertiva em relação a este apoio. Trata-se de uma questão complexa e para a qual, no momento, a manutenção do status quo parece ser a opção que menos prejudica o projeto brasileiro.

Um ponto a ser destacado é aquele relativo ao fato dos dois Estados extrarregionais analisados integrarem a Organização do Tratado do Atlântico Norte. Se os interesses e fatores causais da presença militar da França e do Reino Unido são distintos, existe um forte elo em termos de defesa entre os dois Estados, qual seja: a OTAN, a maior organização de defesa coletiva atualmente existente.

Desde a sua criação em I949, a OTAN nunca teve um de seus Estados-membros desafiado militarmente, sem que os demais integrantes da Organização apoiassem direta ou indiretamente o aliado desafiado. Durante a Guerra das Malvinas esse apoio foi essencial para o esforço de guerra do Reino Unido.

Exceções a esse apoio entre Estados membros da OTAN ocorreram apenas quando a iniciativa do emprego militar partiu unilateralmente de um ou mais dos seus integrantes, caso de Suez em I956 e na invasão do Iraque em 2003. Nesse sentido, a presença militar da França e do Reino Unido constitui um desafio ainda maior à visão brasileira de defesa regional, cabendo 
recordar que a questão das Malvinas ainda é o maior potencial de conflito militar interestatal no Atlântico Sul.

Finalizando, espera-se que a pesquisa realizada possa estimular e contribuir para novos estudos sobre a presença militar de atores exógenos à região e seus reflexos sobre a visão de defesa do Estado brasileiro para a América do Sul e Atlântico Sul. Estudos relativos à presença desses atores extrarregionais e sua interação, presente e prospectiva, com os Objetivos Nacionais de Defesa brasileiros, apresentam-se como desafios acadêmicos promissores em termos de pesquisa e potencialmente relevantes para o constante aprimoramento da visão de defesa brasileira.

\section{REFERÊNCIAS}

Alsina, João Paulo, Sergio W. Etchegoyen and Nelson Jobim A. 20ıo. Segurança Internacional: perspectivas brasileiras. Rio de Janeiro: Editora FGV, 20I0.

Anguera, Manuel Martin; Ayuso, Francisco Bendala; Toledo, Santiago Perez-Seoane de. La Campaña de Las Malvinas. Madrid: San Martin, I985.

BBC. "Britain to boost Falklands Islands defences." Accessed April 2I, 2018. <http://www.bbc.com/news/uk-politics-32031342>.

"Where are British troops deployed overseas?" Accessed April 2I, 20I8. <http://www.bbc.com/news/uk-349I9954>.

"French Guiana: The part of South America facing a total shutdown" (IO April 20I7). Accessed April 29, 20I8. <http://www.bbc.com/ news/world-europe-39557670>.

Brasil. I988. Senado Federal. Constituição da República Federativa do Brasil. Accessed April 2I, 20I8. <http://www.senado.gov.br/legislacao/ const/conig88/CONig88_05.Io.1988/CONig88.pdf>.

. I996. Presidência da República. "Política de Defesa Nacional - PDN". Accessed April 2I, 20I8. <http://www.biblioteca.presidencia.gov.br/ publicacoes-oficiais/catalogo/fhc/politica-de-defesa-nacional-I996. pdf $>$.

2005. Presidência da República. Decreto Nffl 5.484, de 30 de junho de 2005. "Política de Defesa Nacional - PDN". Accessed April 2I, 20I8. <http://www.planalto.gov.br/ccivil_03/_ato2004-2006/2005/ decreto/d5484.htm>.

2008. Presidência da República. Decreto Nffl 6.703, de I8 de dezem- 
bro de 2008. "Estratégia Nacional de Defesa - END". Accessed April 2I, 20I8. <http://www.planalto.gov.br/ccivil_03/_ato20072010/2008/decreto/d6703.htm>.

. 2010. Presidência da República. "Lei Complementar (LC) nffl I36/20I0". Accessed April 2I, 20I8. <http://www.planalto.gov.br/ ccivil_03/leis/LCP/Lcpi36.htm>.

. 20I2a. Ministério da Defesa. "Estratégia Nacional de Defesa - END". Accessed April 2I, 20I8. <http://www.defesa.gov.br/arquivos/20I2/ meso7/end.pdf>.

. 20I2b. Ministério da Defesa "Política Nacional de Defesa - PND”. Accessed April 2I, 20I8. <http://www.defesa.gov.br/arquivos/estado_e_ defesa/END-PND_Optimized.pdf>.

. 20I2c. Presidência da República. Decreto Nffl 7.667, de II de janeiro de 20I2. "Promulga o Tratado Constitutivo da União de Nações Sul-Americanas, firmado em Brasília, em 23 de maio de 2008". Accessed April 2I, 20I8. <http://www.planalto.gov.br/ccivil_03/_ Ato20II-20I4/20I2/Decreto/D7667.htm>.

. 20I6a. Ministério da Defesa. Estratégia "Nacional de Defesa - END" (20I6) - Versão sob Apreciação do Congresso Nacional (Lei Complementar 97/1999, Art. $9^{\circ}, \mathbb{\int} 3^{\circ}$ ). Accessed April 21, 2018. <http://www. defesa.gov.br/arquivos/20I7/meso3/pnd_end.pdf>.

. 20I6b. Ministério da Defesa. "Livro Branco de Defesa Nacional LBDN" (20I6) - Versão sob Apreciação do Congresso Nacional (Lei Complementar 97/1999, Art. 9ㅇ $\left.\int 3^{\circ}\right)$. Accessed April 21, 2018. $<$ http://www.defesa.gov.br/arquivos/20I7/meso3/livro_branco_de_ defesa_nacional_minuta.pdf>.

. 20I6c. Ministério da Defesa. "Política Nacional de Defesa - PND" (20I6) - Versão sob Apreciação do Congresso Nacional (Lei Complementar 97/1999, Art. $9^{\circ}$, $\mathbb{3} 3^{\circ}$ ). Accessed April 2I, 20I8. <http://www. defesa.gov.br/arquivos/20I7/meso3/pnd_end.pdf>.

. Ministério da Defesa. "Brasil e França discutem possibilidades de novas ações de cooperação transfronteiriças". Accessed April 29, 2018. $<$ http://defesa.gov.br/noticias/30245-brasil-e-guiana-francesa-discutem-possibilidades-de-novas-acoes-nas-fronteiras $>$.

. Ministério da Defesa. Exército Brasileiro. Noticiário do Exército (26 de janeiro de 20I8). "Com a inauguração da Brigada da Foz do Amazonas, a presença do Exército Brasileiro na região é reforçada”. Accessed April 29, 20I8. <http://www.eb.mil.br/web/noticias/noticiario-do-exercito/-/asset_publisher/MjaG93KcunQI/content/id/8569649>. 
Collectivite Territoriale de Guyane. "Guyane française: situation géographique”. Accessed April 29, 20I8. <http://www.axl.cefan.ulaval. ca/amsudant/guyanefrr.htm>.

Daily Mail Online. "British nuclear submarine sent to Falklands in show of strength as tensions rise ahead of 3oth anniversary of conflict". Accessed April 2I, 20I8. <http://www.dailymail.co.uk/news/article-2I47045/Sub-way-Falklands.html>.

Empresa Brasil de Comunicação (EBC). "Lançado ao espaço satélite brasileiro que será usado para comunicações e defesa”. Accessed April 29, 2018. <http://agenciabrasil.ebc.com.br/pesquisa-e-inovacao/noticia/20I7-05/lancado-ao-espaco-satelite-brasileiro-que-sera-usado-para>.

Falkland Islands Government. "Results of the referendum on the Political Status of the Falkland Islands". Accessed April 22, 20I8. <https://www. falklands.gov.fk/results-of-the-referendum-on-the-political-status-ofthe-falkland-islands/>.

Folha de São Paulo. "Em apoio à Argentina, Brasil barra embarcação britânica," (I2 de janeiro de 20I2). Accessed April 30, 20I8. <http://wwwI. folha.uol.com.br/fsp/mundo/fti2OI2OIIO2.htm>.

França. 3e Régiment étranger d'infanterie. "Les missions du ze régiment étranger d'infanterie". Accessed January 22, 2018. <http://www.legion-etrangere.com/mdl/info_seul.php?id=463>

Armée de Terre. "ge régiment d'infanterie de marine". Accessed April 22, 20I8. <https://www.recrutement.terre.defense.gouv.fr/regiments/ge-regiment-dinfanterie-de-marine>.

. Centre Spatial Guyanais. "Politique Spatiale". Accessed April 29, 20I8. <http://www.cnes-csg.fr/web/CNES-CSG-fr/9778-politiquespatiale.php>.

Institut national de la statistique et des études économiques (INSEE).

"Recensement de la population en Guyane". Accessed April 28, 20 I8. $<$ https://www.insee.fr/fr/statistiques/3309060>.

. Legifrance.gouv.fr. "Décret $n^{\circ}$ 2009-I405 du I7 novembre 2009 relatif à la consultation des électeurs de la Guyane en application des articles 72-4 et 73 de la Constitution". Accessed April 23, 2018. $<$ http://www.legifrance.gouv.fr/affichTexte.do?cidTexte=JORFTEXTo0002I288022\&fastPos=I\&fastReqId=6I46III44\&categorieLien $=$ cid\&oldAction $=$ rechTexte $>$.

. Livre Blanc 2013 de la Défense et de la Sécurité Nationale. Accessed April 22, 2018. 
<https://www.defense.gouv.fr/content/download/206I86/2286591/file/ Livre-blanc-sur-la-Defense-et-la-Securite-nationale\%202013.pdf> . Marine Nationale. "La Marine en Guyane”. Accessed April 22, 2018. $<$ http://www.defense.gouv.fr/marine/operations/zoom-sur-la-marine-en-outre-mer/annee-de-l-outre-mer-la-marine-en-guyane/la-marine-en-guyane>.

. Marine Nationale. La Marine en Guyane. "Trois missions essentielles pour la Marine en Guyane". Accessed April 22, 2018. <http://www. defense.gouv.fr/marine/operations/zoom-sur-la-marine-en-outremer/annee-de-l-outre-mer-la-marine-en-guyane/trois-missions-essentielles-pour-la-marine-en-guyane>.

. Ministère des Armées. "Les Forces Armées en Guyane". Accessed April 23, 20I8. <http://www.defense.gouv.fr/ema/forces-prepositionnees/guyane/dossier/les-forces-armees-en-guyane>.

. Sénat. "Projet de loi relatif aux collectivités de Guyane et de Martinique". Accessed April 23, 20I8. <http://www.senat.fr/rap/lio-467/lio-4677. html>.

Fontes, Yuri Martins. "Guiana-Caiena se insurge contra exploração colonial francesa”. Accessed April 29, 20I8. <https://alemdarena.blogspot. $\mathrm{com} / 20 \mathrm{I7} / 03 /$ guiana-caiena-se-insurge-contra.html .

Miller, Christopher E. 2005. 2 ed. A Glossary of Terms And Concepts In Peace And Conflict Studies, edited by Mary E. King, 7-Io9. University for Peace. Africa Programme. Accessed June 8, 20I8. https://www.upeace.org/pdf/glossaryv2.pdf

La Nacion. "Confirman que negaron el ingreso a un buque inglés" (I3 de enero de 20II). Accessed April 30, 20I8. <http://www.lanacion.com. ar/I34IO22-confirman-que-negaron-el-ingreso-a-un-buque-ingles>

The Telegraph. "Royal Navy's Falklands ship turned away by Brazil" (ıо Jan 20II). Accessed April 30, 20I8. <http://www.telegraph.co.uk/news/ worldnews/southamerica/falklandislands/8251130/Royal-NavysFalklands-ship-turned-away-by-Brazil.html>.

UNASUR. Archivo Digital de UNASUR. "Estatuto Del Consejo de Defensa Suramericano de La UNASUR”. Accessed April 2I, 20I8. <https:// repo.unasursg.org/alfresco/service/unasursg/documents/content/ ESTATUTO_DEL_CONSEJO_DE_DEFENSA_SURAMERICANO_DE_LA_UNASUR.pdf?noderef=ddb8870e-73fa-4573-bdı2-eec3aaf67f55>.

United Kingdon. Royal Air Force (RAF). "RAF Ascension Island". Accessed April 2I, 20I8. <https://www.raf.mod.uk/our-organisation/stations/ 
raf-ascension-island/>.

. Royal Air Force (RAF). RAF Mount Pleasant. "The Station”. Accessed April 2I, 20I8. <https://www.raf.mod.uk/our-organisation/stations/ raf-mount-pleasant/>.

United Kingdon.Gov.UK. "British forces overseas: Falkland Islands and Ascension Island”. Accessed April 22, 2018. <https://www.gov.uk/guidance/british-forces-overseas-falkland-islands-and-ascension-island>.

"Mount Pleasant Defence Aerodrome Manual 20I7". Accessed April 22, 20I8. <https://www.gov.uk/government/uploads/system/ uploads/attachment_data/file/657078/20170427-Mount_Pleasant_ DAM_VI.o.pdf>.

. Policy. "Falkland Islanders' right to self-determination". Accessed April 22, 20I8. <https://www.gov.uk/government/policies/supporting-the-falkland-islanders-right-to-self-determination > .

Policy Paper. "2010 to 2015 government policy: Falkland Islanders' right to self-determination". Accessed April 22, 20I8. <https://www. gov.uk/government/publications/2010-to-2015-government-policy-falkland-islanders-right-to-self-determination/20Io-to-20I5-government-policy-falkland-islanders-right-to-self-determination>.

United Kingdon.Gov.UK. "Foreign Office Minister Statement on the 35th anniversary of end of the Falkland Islands conflict”. Press release published I4 June 20I7. Accessed April 29, 20I8. <https://www.gov.uk/ government/news/foreign-office-minister-statement-on-the-35th-anniversary-of-end-of-the-falkland-islands-conflict>.

Woodward, Sandy. I997. One hundred days: the memoirs of the Falklands battle group commander. Annapolis, MD: Naval Institute Press.

\section{RESUMO}

A questão das Malvinas catalisa a atenção dos pesquisadores nos estudos relativos à presença militar de atores extrarregionais na América do Sul. Contudo, a França, um Estado igualmente exógeno às nações sul-americanas, se faz presente na região, mantendo um território colonial, onde se encontram posicionados contingentes e instalações militares, quase sempre ignorados nos estudos de segurança regional. Neste contexto, o artigo tem como objetivo evidenciar a presença militar da França e do Reino Unido na América e Atlântico Sul e analisar as tensões decorrentes dessa presença, em relação à visão brasileira de defesa para a região.

\section{PALAVRAS-CHAVE}

Atlântico Sul; América do Sul; Segurança Regional. 